\title{
PRODUÇÕES E PRODUTOS CULTURAIS NA SALA-DE-AULA: UMA ANÁLISE CRÍTICO-DIALÓGICA DO FANDOM DE HARRY POTTER E DA FRANQUIA MEU MALVADO FAVORITO
}

\author{
PRODUCCIONES Y PRODUCTOS CULTURALES EN EL AULA DE CLASE: UN \\ ANÁLISIS CRÍTICO-DIALÓGICO DEL FANDOM DE HARRY POTTER Y DE LA \\ FRANQUÍA MI VILLANO FAVORITO
}

\section{PRODUCTIONS AND CULTURAL PRODUCTS IN THE CLASSROOM: A CRITICAL- DIALOGICAL ANALYSIS OF THE HARRY POTTER FANDOM AND DESPICABLE ME FRANCHISE}

\author{
Luciane de PAULA ${ }^{1}$ \\ Ana Beatriz Maia BARISSA ${ }^{2}$ \\ Natasha Ribeiro de OLIVEIRA ${ }^{3}$
}

RESUMO: Este artigo se propõe a pensar as produções culturais, transformadas em produtos de consumo, em sala-de-aula, como estratégias dialógicas de formação crítica. A proposta é refletir sobre a presença dessas produções e produtos a partir de duas obras icônicas da indústria cultural por sua viralidade: Harry Potter e Meu Malvado Favorito - a maior comunidade de fandom do mundo e o sucesso dos minions, especificamente no Brasil. A fundamentação teórica se pauta nos estudos bakhtinianos em diálogo com a teoria crítica. Harry Potter será pensado por meio da produção dos fãs e Meu Malvado Favorito nos campos de atuação a partir da imagem dos minions. Pretende-se pensar sobre a relação escola e sociedade, bem como acerca da constituição da vida na escola como formação cidadã, e esta é a sua relevância.

PALAVRAS-CHAVE: Teoria Crítica. Estudos bakhtinianos. Diálogo. Cultura da convergência. Transmídia.

RESUMEN: El artículo propone pensar las producciones culturales, trasformadas en productos de consumo, en aula de clase, como estrategias dialógicas de formación crítica. La propuesta es reflexionar sobre la presencia de estas producciones y productos a partir de dos obras icónicas de la industria cultural por su viralidad: Harry Potter y Mi Villano Favorito la mayor comunidad de fandom del mundo y el suceso de los minions, específicamente en Brasil. La fundamentación teórica se basa en los estudios bakhtinianos en diálogo con la teoría

${ }^{1}$ Universidade Estadual Paulista (UNESP) Faculdade de Ciências e Letras de Araraquara e Faculdade de Ciências e Letras de Assis - SP - Brasil. Docente do departamento de Linguística da FCL Assis e credenciada no Programa de Pós-Graduação em Linguística e Língua Portuguesa da FCL Araraquara. ORCID: https://orcid.org/0000-00031727-0376. Lattes: http://lattes.cnpq.br/9546185363173636. E-mail: lucianedepaula1@ gmail.com

${ }^{2}$ Universidade Estadual Paulista (UNESP), Araraquara - SP - Brasil. Mestre em Linguística e Língua Portuguesa pelo Programa de Pós-Graduação em Linguística e Língua Portuguesa. ORCID: https://orcid.org/0000-0003-02290892. Lattes: http://lattes.cnpq.br/2348908556314422. E-mail: anabeatrizbarissa@gmail.com

${ }^{3}$ Universidade Estadual Paulista (UNESP), Araraquara - SP - Brasil. Mestranda do Programa de Pós-Graduação em Linguística e Língua Portuguesa. Pesquisa apoiada pela FAPESP/CAPES Processo n 2017/26629-3. ORCID: https://orcid.org/0000-0001-8760-8104. Lattes: http://lattes.cnpq.br/8039551360391713. E-mail: nariiibeiro@gmail.com 
crítica. Harry Potter será pensado por medio de la producción de los fans y Mi Villano Favorito en los campos de actuación a partir de la imagen de los minions. Se pretende pensar sobre la relación escuela y sociedad, así como sobre la constitución de la vida en la escuela como formación ciudadana. $Y$ esta es su relevancia.

PALABRAS CLAVE: Teoría crítica. Estudios bakhtinianos. Diálogo. Cultura de la convergencia. Transmedia.

ABSTRACT: This article aims to think of cultural productions, transformed into consumer products, in the classroom, as dialogic strategies of critical formation. The proposal is to reflect on the presence of these productions and products from two iconic works of the cultural industry for their virality: Harry Potter and Despicable Me - the world's largest fandom community and the success of minions, specifically in Brazil. The theoretical foundation is based on Bakhtinian studies in dialogue with critical theory. Harry Potter will be thought through the production of fans and Despicable Me in the fields from the image of the minions. It is intended to think about the relationship between school and society, as well as about the constitution of school life as a citizen formation, and this is its relevance.

KEYWORDS: Critical theory. Bakhtinian studies. Dialogue. Convergence of culture. Transmedia.

\section{Introdução}

A proposta deste artigo é refletir sobre o uso de mídias e redes sociais em contexto escolar. Utilizamos produções inspiradas em Harry Potter (doravante, HP) e Meu Malvado Favorito, entendidas como práticas sociais, estudadas como produtos da indústria cultural, da cultura da convergência e da transmídia.

A indústria cultural, tal qual concebida pelos pensadores da Escola de Frankfurt, percebeu que as produções atingem um grande número de pessoas (público) com os mais diferentes tipos de mídias e, com essa produção massificada, em larga escala e altamente difundida, gera uma concepção mercadológica sobre a arte e a cultura. Com os estudos críticos culturais, compreendemos não só a massificação, mas como esse fenômeno se relaciona com o comportamento dos sujeitos, com a homogeneização do pensamento e com os padrões de consumo, consequência da mercantilização da arte.

O pensamento de que o sujeito é acrítico e incapaz de refletir é uma concepção que desconsidera o seu caráter responsável e responsivo, tão caro aos estudos bakhtinianos, que pautam sua filosofia na interação como ato. Refletimos, aqui, sobre a relação entre as produções 
massivas e a respondibilidade do sujeito ${ }^{4}$ (BAKHTIN, 2010) como condição da atuação humana no mundo e na realidade social que o cerca.

Com o uso cada vez mais intenso e normalizado das novas tecnologias e das mídias sociais nas diferentes esferas e com a utilização de diferentes usos da linguagem, há uma demanda, sobretudo na esfera escolar, por um ensino aberto e crítico. Isso pede uma prática pedagógica interativa e reflexiva, que dê conta da heterogeneidade da linguagem, constituída pela e na cultura em gêneros do discurso ${ }^{5}$, produzidos em esferas das mais diversas e em interseção, mediada pelas tecnologias; assim como pensar de que maneira o sujeito tem se relacionado com o mundo que o cerca, dentro e fora da sala-de-aula - principalmente ao que concerne à indústria cultural, tema desta reflexão.

Dois exemplos ilustram a reflexão aqui empreendida: o primeiro, relacionado ao fandom ${ }^{6}$ de Harry Potter, para pensar como a produção ativa e criativa dos fãs, que parte de uma obra considerada como "cultura de massa", traz novas formas de uso da(s) linguagem(ns); e, o outro, calcado nos minions, da franquia Meu Malvado Favorito, para refletir sobre como a indústria cultural invade outras esferas, como os campos de atuação se inter-relacionam e se deslocam pelas mídias, do entretenimento à política.

A justificativa pela escolha de trabalho com essas duas produções se pauta na expressividade do fandom de HP e na viralização dos minions. Ambos, líderes em vendagens e em proliferação de produtos de consumo. O critério metodológico se calçou nos fenômenos que se tornaram essas duas produções, que extrapolaram as telas do cinema e ganharam a sociedade nas mais diferentes áreas. Levarmos as questões de produção e consumo para a escola nesse momento sócio-histórico, da cultura da convergência, em que a transmídia integra a vida dos sujeitos, é essencial.

Pensar nas mídias sociais como parte da vida do aluno (e da maioria dos sujeitos) é condição primordial para que não se tenha uma visão proibitiva e limitadora nas salas-de-aula sobre o uso de aparelhos eletrônicos e redes sociais, pois eles possibilitam o surgimento de diferentes debates e questionamentos, uma vez que são uma das formas de comunicação mais utilizadas atualmente. Knebel e Hildebrand (2013) pensam na tecnologia como um instrumento de ensino-aprendizagem, pois acreditam que dali provém diferentes possiblidades de fazer com

${ }^{4} \mathrm{O}$ Círculo concebe sujeito eu e outro, em interação, com foco na alteridade, constitutiva da identidade. As vozes sociais se materializam nos sujeitos, constituídos pela e na linguagem.

${ }^{5}$ Discurso, nos estudos bakhtinianos, diz respeito à produção semiótica tridimensional da linguagem, concebida pelo verbal, pelo vocal/sonoro e pelo visual, materializada em enunciados configurados de diferentes maneiras, mas potencialmente presentes em toda manifestação linguageira.

${ }^{6} \mathrm{O}$ universo de produções dos fãs recebe este nome, que é diminutivo de fan kingdom ("reino dos fãs").

RIAEE - Revista Ibero-Americana de Estudos em Educação, Araraquara, v. 14, n. esp. 4, p. 2071-2087, dez., 2019. E-ISSN: $1982-5587$. 
que o aluno tenha uma relação positiva frente às questões escolares. As redes sociais são canais de socialização, e a interação possibilitada é o princípio transformador para uma abordagem crítica.

As tecnologias e mídias sociais, hoje, são vistas como parte integrante das relações sociais e se vinculam à ideia de mundo em movimento, o que permite aos alunos (sujeitos sociais) construírem novas formas de perceber, interpretar, aprender e agir sobre o mundo que os rodeia. Segundo Knebel e Hildebrand, "Blogs, redes sociais, websites não são meros mecanismos distributivos de informação ou de formas de entretenimento, eles agem sobre os diferentes contextos humanos, operando verdadeiras metamorfoses nos relacionamentos e nos processos cognitivos" (2013, p. 104).

Por isso, propomos, com esse estudo, uma reflexão acerca do uso de tecnologias e mídias sociais como uma forma de compreensão de processos culturais que, muitas vezes, são encarados como alheios, proibidos e externos à sala-de-aula. Para tanto, pensamos em como a indústria cultural, a cultura da convergência e a transmídia compõem, de certa forma, as relações sociais e influenciam os comportamentos dos sujeitos que consomem suas produções e produtos (físicos e simbólicos).

Dessa forma, justifica-se a importância de pensarmos essas produções e esses produtos como linguagem e como prática social a ser estudada na escola, pois as obras fílmicas e literárias, como Harry Potter e Meu Malvado Favorito, não só são objeto de consumo dessa indústria cultural oficial, enquanto superestrutura ideológica, como também são as fontes pelas quais os sujeitos se colocam no mundo enquanto participantes dessa cultura participativa e colaborativa.

\section{Indústria cultural, cultura da convergência e transmídia}

Adorno e Horkheimer, da Escola de Frankfurt, utilizaram o termo "indústria cultural" para designar a situação da arte na sociedade capitalista industrial como algo mais maléfico do que benéfico. No texto "O Iluminismo como mistificação das massas", presente na obra Indústria cultural e sociedade (2002), os autores afirmam que

O cinema e o rádio não têm mais necessidade de serem empacotados como arte. A verdade de que nada são além de negócios, lhes serve de ideologia. Esta deverá legitimar o lixo que produzem de propósito. O cinema e o rádio se auto definem como indústrias, e as cifras publicadas dos rendimentos de seus diretores-gerais tiram qualquer dúvida sobre a necessidade social de seus produtos (2002, p. 5-6).

RIAEE - Revista Ibero-Americana de Estudos em Educação, Araraquara, v. 14, n. esp. 4, p. 2071-2087, dez., 2019. E-ISSN: 1982-5587. 
A indústria cultural se volta à padronização e massificação de seus produtos, resultado de um modelo de arte voltado para os negócios, lucros e capital, não para a arte, em si. A Escola de Frankfurt vê a produção da arte em larga escala como uma banalização e concebe o público como consumidor desprovido de capacidade crítica, consumidor massivo dos produtos da indústria cultural veiculados pelas diferentes mídias. Para essa Escola, arte e indústria cultural configuram uma relação dicotômica, em que não podem ser concebidas em conjunto, uma vez que a arte autônoma não se iguala à industrial, voltada a um público "mediano".

Há, pelo menos, dois preconceitos nesse pensamento: 1) a ideia purista sobre arte, vista como algo superior às leis sociais, logo, mercadológicas, pois mesmo antes da indústria cultural, o artista (e o intelectual também) produzia, muitas vezes, sob encomenda e/ou proteção do Mecenas (alguns exemplos canônicos são Michelângelo e Velásquez, nas artes plásticas, Gil Vicente e Camões, nas Letras); 2) a noção subestimada acerca do público, entendido como nãopensante e, de certa forma, "marionete" nas mãos do sistema. Nesse caso, como pensar a resistência, muitas vezes, produzida a partir do consumo, respondido de maneira crítica, como ocorre, por exemplo, com Cervantes, Shakespeare ou algumas produções advindas de fandom, hoje? Essas questões, de embate guiam nossa reflexão e nos levam a pensar sobre a relação produção-consumo-recepção ativa, na sala-de-aula, como pauta educacional.

O pensamento da Escola de Frankfurt contribui sobremaneira para pensarmos em como a indústria cultural é responsável pelo movimento de massificação, este, tanto como processo alienador, como estudado por Adorno, por exemplo; quanto como popularização da arte, que chega a lugares antes não imaginados. Essa linha ambivalente, entre contrários e contraditórios (dialética), é o que propomos ser objeto de reflexão na e da escola, enquanto forma de emancipação da robotização e tomada de consciência da responsabilidade dos sujeitosconsumidores, como também novos produtores sociais que pensam sobre o que leem e veem (não meras máquinas de curtidas e compartilhamentos) - tema tão caro, especialmente, em época de Fake News, da chamada era da pós-verdade. O massivo faz circular a obra (pensando que nosso objetivo é pensar na produção, recepção e circulação social de textos/discursos). O filme, a literatura e outros gêneros não são meros reprodutores de valorações hegemônicas, mas também apropriadores de valorações cotidianas que circulam e são apropriadas e ressignificadas em um outro plano e com outra elaboração de linguagem.

O movimento dialético-dialógico (PAULA; FIGUEIREDO; PAULA, 2011) é ininterrupto: as superestruturas respondem a uma demanda social infraestrutural que, quando oficializada, volta em formato de obra de consumo e produtos culturais. A indústria (na 
superestrutura) utiliza a recepção como termômetro para o que o público consome mais, menos ou continua consumindo mesmo depois de passadas as chamadas "febres do lançamento" (como é o caso tanto de $H P$ quanto dos minions). Nem os produtores nem os consumidores são passivos, pois a adesão a uma produção e a um produto refletem e refratam práticas que constituem um perfil responsivo a valorações sociais. O consumo é, então, ato de linguagem, posicionamento no mundo.

Volóchinov (2017 [1929]) pensa na ideologia do cotidiano (nascida e realizada na infraestrutura) como força centrífuga determinante para o processo de resistência à superestrutura, onde é produzida a ideologia oficial e também se situa a indústria cultural, como força centrípeta que objetiva a homogeneização e hegemonia. O autor vê na palavra (tomada em seu sentido alargado), enquanto signo ideológico por excelência, a resposta (que deve ser de tomada de consciência possível e, aqui, entra o papel da escola: colaborar para a conscientização desse processo de embate), que reflete e refrata a luta de classes no discurso (arena onde se digladiam os valores sociais contraditórios).

Volóchinov afirma que "Na palavra se realizam os inúmeros fios ideológicos que penetram todas as áreas da comunicação social. É bastante óbvio que a palavra será o indicador mais sensível das mudanças sociais" (2017, p. 106 - grifos do autor), o que nos faz pensar em como a ideologia do cotidiano não só é parte constitutiva da ideologia oficial, como também a nega, pois responde a ela de maneira responsável (sem álibi da existência). Por isso, não entendemos o comportamento massivo apenas como alienação (ausência de criticidade), processo automático de padronização unilateral em que só a superestrutura atua. O diálogo mantém vivas as forças discursivas.

Segundo Jenkins,

[...] a cultura da convergência é altamente produtiva: algumas ideias se espalham de cima para baixo, começando na mídia comercial e depois adotadas e apropriadas por uma série de público diferentes, à medida que se espalham por toda a cultura. Outras surgem de baixo para cima, a partir de vários pontos da cultura participativa, e são arrastadas para a cultura predominante, se as indústrias midiáticas vislumbrarem algum modo de lucrar com elas. O poder da mídia alternativa é que ela diversifica; o poder da mídia de radiodifusão é que ela amplifica (2009, p. 341)

Nesse sentido, perguntamos: como a cultura da convergência está em consonância com a indústria cultural, bem como com o pensamento bakhtiniano, ao que concerne à ideologia oficial e à do cotidiano? A cultura é produtiva em diferentes sentidos, uma vez que coloca a oficialidade e a não-oficialidade em embate, de modo que, cada qual à sua maneira, trabalha 
com determinado conteúdo temático proveniente de uma produção no formato de obra de consumo.

\section{Diálogo entre gêneros e esferas}

As produções e produtos culturais são, em essência, atos de linguagem. De acordo com o pensamento bakhtiniano, a "unidade do meio social" e a "unidade do acontecimento da comunicação social” (VOLÓCHINOV, 2017 [1929], p. 147) determinam, junto com o conjunto físico-psicofisiológico, a língua-discurso. O social desempenha função essencial para as questões da linguagem, visto que só conseguimos observar sua manifestação (configuração enunciativa) diante de indivíduos socialmente organizados em uma mesma coletividade linguística, segundo o autor.

Ao que se refere à linguagem e às mais diferentes configurações possibilitadas pelas esferas da atividade humana, temos, no virtual, uma importante forma de interação feita pelos sujeitos. Segundo Lévy (2000),

[...] o virtual é obviamente uma dimensão muito importante da realidade. [...] Em geral acredita-se que uma coisa deva ser ou real ou virtual, que ela não pode, portanto, possuir as duas qualidades ao mesmo tempo. Contudo, [...] o virtual não se opõe ao real mas sim ao atual: virtualidade e atualidade são apenas dois modos diferentes da realidade (p. 47)

Segundo o autor, embora o digital seja "[...] fluido, em constante mutação, seja desprovido de qualquer essência estável [...] a velocidade de transformação (das informações) é em si mesma uma constante - paradoxal - da cibercultura" (p. 27). Isso nos leva a pensar, pautados em Bakhtin (2011), nos gêneros discursivos e em sua relativa estabilidade. Para tanto, é necessário ter em vista todo o contexto que suscita e possibilita o surgimento de novos gêneros, como é o caso das produções de fãs, no formato de fanfilms (como há no fandom de $H P$ ), de posts em páginas do Facebook. Produções que intersecionam entretenimento e política, como novas configurações e significações (caso dos minions desde a campanha presidencial de 2018), tanto nas redes sociais quanto em outros canais de comunicação e em esferas as mais diversas.

A importância das mídias nas interações entre sujeitos na contemporaneidade é fundamental. Nessas e dessas interações resultam produções diversas, compreendidas como posicionamentos axiológicos. Conforme Machado (2014), as esferas de uso da linguagem se 
configuram como uma referência direta aos enunciados ${ }^{7}$. Na mídia, usuários têm possibilidade de escolher/posicionar-se acerca do conteúdo a ser consumido e como isso ocorrerá, sempre de maneira responsiva.

Conforme Jenkins (2006), a participação conjunta dos usuários de mídia constitui a ideia de inteligência coletiva - processo fundamental para a concepção de transmídia -, uma vez que a publicação de posts, vídeos, imagens nas diversas plataformas incitam outros tipos de contribuições: as réplicas. A partir de uma postagem, haverá respostas em concordância ou em discordância que, por sua vez, incitarão novas respostas outras. Esse processo só é possível de ser observado por estar inserido em uma determinada esfera de atividade.

A concepção de linguagem do Círculo de Bakhtin está fundamentada no diálogo ${ }^{8}$, pois ultrapassa as estruturas linguísticas e se torna constitutiva do sujeito. A materialização enunciativa só é possível no processo de interação social. Isto é, a linguagem só se constitui a partir da/na relação entre sujeitos (e) enunciados. Para o Círculo russo, o signo não pode estar desvinculado do seu horizonte social e o extralinguístico é parte do signo: forças centrípetas e centrífugas entram em jogo dentro do signo e revelam o posicionamento axiológico das vozes em embate.

Todo e qualquer enunciado surge em uma esfera e nela circula. Refletem e refratam um horizonte social ideológico específico e, por conseguinte, as necessidades de sua interação em um determinado projeto de dizer - conteúdo, forma e estilo. Ao discutir sobre esfera ideológica, Medviédev (2012) ressalta que cada uma, com suas formas e métodos específicos, possui peculiaridades imprescindíveis, que precisam ser consideradas ao analisarmos um enunciado. Para o autor, a especificidade das artes não deve encobrir a unidade ideológica dos campos (infra e superestrutura) sobre uma base única, com uma lei única socioeconômica. A plurivalência semiotiza a heterogeneidade.

Sobre esse movimento enunciativo, o Círculo afirma que as relações são determinadas pela estrutura das formas ideológicas, definidas pelas necessidades de uma esfera. Os campos são responsáveis por transpassar a realidade a partir de um determinado horizonte social e, por meio dele, construir sentido, de acordo com a sua peculiaridade. A singularidade influencia o

${ }^{7}$ Enunciado, para o Círculo bakhtiniano, assim como os gêneros, também é composto por conteúdo, forma e estilo. Não há, segundo os autores, enunciado sem gênero, pois ele é produzido em ato, numa esfera de atividades específica, como acontecimento vivo. Caracteriza-se o enunciado, ao mesmo tempo, por sua singularidade e como elo que o engata na corrente discursiva. É ele, concomitantemente, processo e produto social, constituído de sujeitos e situacionalizado/contextualizado num tempo-espaço específico em diálogo com outros sujeitos, tempos e espaços, dado o seu caráter responsivo.

${ }^{8}$ Diálogo, para Bakhtin, é mais que discurso direto, face-a-face, mas embate de vozes sociais, com valores contrários e contraditórios em jogo. Um jogo dialético sem solução, em que não há final, mas pontos de vista colocados na arena discursiva, de maneira responsiva e responsável.

RIAEE - Revista Ibero-Americana de Estudos em Educação, Araraquara, v. 14, n. esp. 4, p. 2071-2087, dez., 2019. E-ISSN: $1982-5587$. 
conteúdo temático, a forma composicional e o estilo de um enunciado e determina o gênero discursivo, relativamente estável.

Para o autor, a riqueza e a diversidade dos gêneros se encontram nas possibilidades da atividade humana, “[...] porque em cada campo dessa atividade é integral o repertório de gêneros do discurso, que cresce e se diferencia à medida que se desenvolve e se complexifica um determinado campo." (BAKHTIN, 2011, p. 262). Os gêneros não podem ser observados como formas fixas, uma vez que é necessário considerar o movimento das relações interpessoais e ideológicas, além do contato com outros gêneros, para se analisar e produzir um enunciado genérico. Para refletirmos sobre isso, embasamo-nos na concepção de diálogo para pensar sobre o embate entre produção e produto cultural nas escolas, como jogo entre alienação e resistência.

\section{A aula como acontecimento: produções e produtos culturais na escola}

A sala-de-aula deve pensar no aluno como sujeito social, no tempo-espaço de sua inserção e na linguagem como interação. Essa deve ser a condução norteadora de uma prática pedagógica crítica, que considera as vivências sociais como baliza educacional, que deve considerar a realidade existente (seja a infraestrutura física, a configuração dos métodos e abordagens e, principalmente, a realidade social, econômica e cultural dos alunos). Conforme Geraldi (2015), a aula como acontecimento é uma conquista da escola, uma prática pedagógica que queremos alcançar.

Pensar os sujeitos em suas heterogeneidades discursivas e sociais significa inclui-los não como mero receptores passivos, acríticos e distantes da prática pedagógica, pois não envolvidos diretamente com as questões postas em sala-de-aula e na escola, mas sim como sujeitos ativos e participativos, tanto do processo educacional de sua formação quanto das produções culturais experienciadas, individual e coletivamente, que precisam ser inclusivas. $\mathrm{O}$ sujeito atua no mundo por meio da linguagem e, assim, só pode transformá-lo, também, pela linguagem:

A leitura do mundo e a leitura da palavra são processos concomitantes na constituição dos sujeitos. Ao "lermos" o mundo, usamos palavras. Em cada palavra, a história das compreensões do passado e a construção das compreensões do presente que se projetam como futuro. Na palavra, passado, presente e futuro se articulam (GERALDI, 2015, p. 32).

O caráter de responsabilidade e responsividade do sujeito e do enunciado se tornam evidentes nas palavras de Geraldi, que ecoam Bakhtin ao tratar da existência como ato singular 
e único: "[...] ser realmente na vida significa agir, é ser não indiferente ao todo na sua singularidade" (BAKHTIN, 2012, p. 99), porque “[...] tudo em mim - cada movimento, cada gesto, cada experiência vivida, cada pensamento, cada sentimento - deve ser um ato responsável” (p. 101). O sujeito não possui álibi em sua existência. O viver é dialógico, em todas as esferas da atividade humana. A escola e a sala-de-aula são exemplos de lugares pensados como articulação do presente, passado e futuro, que consideram o aluno como sujeito social, produtor de textos/discursos (linguagem), entendidos como atos sociais, seja em qual materialidade enunciativa for.

Esta reflexão se volta à importância de pensarmos, em sala-de-aula, as leituras de mundo do aluno-sujeito, pois elas revelam práticas sociais a serem consideradas em sua formação, o que demanda trazermos as produções e os produtos culturais. Como justificado na introdução, pautamo-nos em dois fenômenos midiáticos: HP e minions.

A proporção da recepção dos livros e filmes de $H P$ resultou em uma quantidade incontável de trabalhos de fãs que, com o suporte das plataformas midiáticas, colocaram-se em uma outra posição: a do leitor-produtor, o leitor-autor ou autor-fã.

O posicionamento do fã toma forma por meio da criação de outras obras a partir do enunciado-fonte, divulgadas em plataformas e redes do fandom: fanvideos, fanarts, fanfictions, cosplays, etc. Essas obras são, muitas vezes, desprezadas pela escola, consideradas sem valor ou até desconhecidas. Com essa postura, não é apenas a produção linguageira sistêmica que a escola descarta, mas revela o seu desprezo às vozes e às vidas dos alunos, como se nada tivesse a ver com suas experiências. Nem se propõe a conhecer e essa resposta gera uma outra, o desinteresse pelos conteúdos programáticos, transmitidos aos alunos como se eles fossem uma "folha em branco" a ser preenchida. Não, eles são sujeitos repletos de história, com desejos e opiniões.

Levar para a sala-de-aula as produções dos alunos a partir de obras massivas pode ser um start para despertar interesse, para discutir questões de alienação e despertar a consciência, inserir os multiletramentos nas aulas e dar vez a sujeitos que possuem suas vozes silenciadas, como quem nada sabe e, portanto, nada têm a dizer.

De acordo com os estudos bakhtinianos, se toda produção enunciativa é responsiva, ao negar voz aos alunos, a resposta obtida pela escola é indisciplina, apatia e acriticidade. Essa é a escola que queremos? Composta por sujeitos disciplinados, que aprendem a se submeter e a responder em contextos avaliativos, pressionados por punição ou premiação, com base numa política condenável do "toma lá, dá cá"? Como exigir o desenvolvimento do senso crítico e a possibilidade de exercício pleno da cidadania de um sujeito que passa a vida aprendendo a RIAEE - Revista Ibero-Americana de Estudos em Educação, Araraquara, v. 14, n. esp. 4, p. 2071-2087, dez., 2019. E-ISSN: 1982-5587. DOI: https://doi.org/10.21723/riaee.v14iesp.4.12935 
responder o que o sistema entende como "bom" e "correto" para classificar os sujeitos, com base num ensino tecnicista e conteudista (conteúdos que nada têm a ver com a vida do aluno)?

Talvez esteja passada a hora da escola pensar sobre o papel das redes sociais, sobre as múltiplas competências e nos sentidos de estímulo ou transformação social. Talvez, começar a pensar as produções e os produtos massivos, na era da cultura da convergência e da transmídia, seja uma forma de quebrar barreiras de preconceitos, extrapolar muros e enxergar o aluno como sujeito social ativo, como ser vivo.

As narrativas, contempladas como conteúdo a ser trabalhado no ensino fundamental, por exemplo, podem ser uma entrada salutar para a interação a partir do fandom, em cotejo com outros enunciados, de diversos gêneros (poesia, microconto, crônica, artigo de opinião, editorial, propaganda, letra de canção, relato, entre outros). Isso pode ser feito com os mesmos procedimentos usados espontaneamente pelos fãs, em suas plataformas digitais: um personagem, a mudança de um trecho do enredo etc. Com isso, é possível trabalhar a estrutura narrativa, estudá-la de maneira viva, em diálogo com outras estruturas textuais/discursivas, utilizar as tecnologias como ferramentas de aprendizagem, pensar outros letramentos etc.

A criatividade da aula, que pode ter um tema transversal, trabalhado por um ou vários professores, com disciplinas em diálogo, a partir da construção autônoma do aluno, pode produzir um efeito muito diferente do robotizado existente, que "copia" e "cola", como "curte" e "compartilha" sem pensar, engolindo qualquer informação como verdade, a partir de crença advinda de qualquer discurso de autoridade (que não se pode nem deve questionar). Ao contrário. Com liberdade ao invés de opressão, o aluno-sujeito pode tomar consciência dos processos de alienação e se insurgir contra o sistema. Esse, aliás, é o papel revolucionário (temido, por isso, tomado como inimigo por governos autoritários) da educação: desenvolver a criticidade.

Mas a criticidade só pode ser estimulada e desenvolvida por meio de textos considerados apropriados ou "superiores" (a que?), enaltecidos como mais adequados ou "melhores"? Não necessariamente. Toda produção é material de estudo. Se, por um lado, a escola tem o papel fundamental de proporcionar conhecimento de registros linguísticos e textos que o aluno desconhece, por outro, ela também tem a função de ensinar o convívio respeitoso com a diferença de pontos de vistas, sujeitos e grupos. Para isso, usar a heterogeneidade de que é composta a sala-de-aula, microcosmo social, é um exercício vivo de cultura e cidadania. Logo, fazer da escola um espaço de troca de saberes e de cada aula um evento único é a proposta que parece ser a única forma de fazer acontecer a vida em ato, singular e coletivo, elo na cadeia discursiva. 
A guisa de ilustração de como isso pode ser feito, trazemos um exemplo: dentre as diversas possibilidades de escritas dos fãs de Harry Potter, um dos ganchos de maior discussão concerne à figura de Severo Snape, personagem de muita complexidade na série - não só por seu comportamento, mas também pelo seu final narrativo. Fãs abrem discussões na tentativa de compreender a natureza do personagem, colocado na comunidade em dois extremos: como herói ou como vilão.

Tal qual a Warner Bros fez para divulgar o último filme de HP, a Broad Stroke Productions também divulgou cartazes em seu site oficial e página de Facebook, a fim de promover o fanfilm que produziu a partir dos livros e dos filmes de HP:

Figura 1 - Cartazes de divulgação do Fanfilm e de Harry Potter

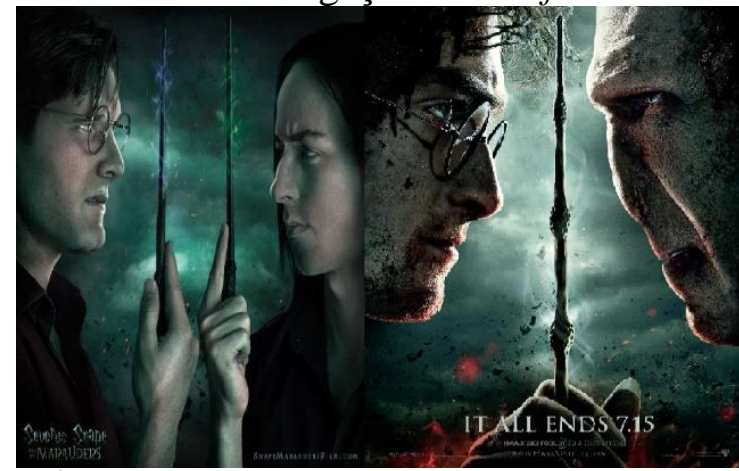

Fonte: Severus Snape Fanfilm ${ }^{9}$ e Veja Abril ${ }^{10}$

Levar cartazes de divulgação dos filmes para a aula, analisá-los, estudar a construção arquitetônica do gênero e produzir com os alunos outros cartazes é um exemplo de estratégia de aula, dentre tantas atividades possíveis.

Pensar HP e as mídias de seu fandom na escola demanda considerar a recepção da saga de forma ativa, com várias produções em diversas formas. Esse processo subjaz a prática social do aluno-fã a partir de sua relação com os livros e filmes.

Uma outra proposta de trabalho seria: estimular a leitura dos livros e dos filmes e elaborar atividades de leitura e escritura conjunta com os alunos para discussão das obras. É possível dividir a sala e distribuir as leituras dos livros e dos filmes por grupos.

${ }^{9}$ Este fanfilm foi objeto de estudo do mestrado de Ana Beatriz Maia Barissa, uma das autoras deste artigo. Sua dissertação, defendida em 2019, intitula-se por e para fãs: Uma análise dialógica de Severo Snape em uma produção transmidiática (não publicada).

10 Disponível, respectivamente, em: http://snapemaraudersfilm.com/media/ e https://abrilveja.files.wordpress.com/2016/06/poster-de-harry-potter-e-as-reliquias-da-morte-parte-2original.jpeg. Acesso em: 31 maio 2019.

RIAEE - Revista Ibero-Americana de Estudos em Educação, Araraquara, v. 14, n. esp. 4, p. 2071-2087, dez., 2019. E-ISSN: $1982-5587$. DOI: https://doi.org/10.21723/riaee.v14iesp.4.12935 
Depois, pedir que cada grupo apresente a sua leitura para a sala, em forma de jornal falado ou seminário, com ou sem teatralização de alguma cena expressiva; levantar pontos enfatizados na obra e trabalhá-los de maneira transversal (alguns exemplos são: ditadura, fascismo, nazismo, hierarquia social, disputa de poder, racialização, entre outros - em conjunto ou não com o professor de história).

Em seguida, perguntar quem conhece o fandom de $H P$ e propor, a partir do conhecimento de mundo deles, atividades de produção de narrativas, adentrando no universo dos multiletramentos e no letramento digital (fanfiction em blogs e plataformas específicas, fanzines, confecção de cartazes e outros tipos de propagandas dos filmes, documentários, entrevistas, relatos, etc., com os mais diversos materiais como suporte - com ou sem a colaboração do professor de artes ou de informática, por exemplo).

Diversos gêneros podem ser trabalhados em contato, e os alunos, leitores de uma obra massiva, mais que receptores reprodutores alienados, a partir de um universo que conhecem, são encarados como sujeitos ativos, produtores de outros enunciados, pessoas que se posicionam por aprender que a sua produção e a sua voz têm valor.

Um outro exemplo diz respeito especificamente aos produtos culturais (mais do que às produções, caso de $H P$ ). Os minions são personagens que saem da arte massiva do filme de animação e ganham vida, em diferentes campos da atividade humana, como produtos de consumo, sempre em diálogo intrínseco com a obra-fonte.

$\mathrm{Na}$ franquia, os minions são colocados como servos e explorados pelo seu trabalho por Gru, o patrão, "malvado favorito", explorador do trabalho dos minions. Contrário ao que se esperava, os minions passaram de coadjuvantes sem importância (sem nomes, sem domínio linguístico, uma massa de operários) ao centro das atenções pelo sucesso que fizeram com o público. Os minions saíram das telas do cinema e invadiram todas as esferas e produtos. Tornaram-se uma grande "febre amarela"11, pois há minions em diferentes enunciados e produtos de consumo à nossa volta.

Os sujeitos-alunos atuam ativamente no ciberespaço (LÉVY, 2000), que propicia a criação de diferentes tipos de interação, constroem um outro tipo de diálogo com as tecnologias e as mídias sociais. Os minions circulam, em forma de produto de consumo físico, nos mais diferentes tipos de lojas e segmentos: gôndolas de supermercados, lojas de roupas, calçados e brinquedos, papelarias, festas de aniversário, dentre outras possibilidades (licenciadas ou não).

${ }^{11}$ A epidemia que se tornou culturalmente os minions é a tese defendida na dissertação de mestrado intitulada $A$ febre amarela "minions": uma análise bakhtiniana, em andamento (ainda não publicada, a ser defendida até o final de 2019), por Natasha Ribeiro de Oliveira, uma das autoras deste artigo. 
Eles não se limitam somente ao consumo físico, mas também ao consumo simbólico, ou seja, a ideia de minions e o que eles significam.

No campo do entretenimento são diversas as páginas que trazem montagens dos minions (recortes de cenas dos filmes) com alguma frase popular e já conhecida pela maioria dos sujeitos que usa o Facebook. No campo político, contudo, os minions originaram um outro termo, amplamente difundido e utilizado desde o período eleitoral brasileiro de 2018: "bolsominions". Criado por um grupo de oposição ao político Bolsonaro e utilizado para designar o eleitorado político que o apoia, o termo bolsominions ou simplesmente minions, na esfera política coloquial, viralizou de tal forma que até o grupo denominado "bolsominions" se apropriou dele, como uma estratégia discursiva de esvaziamento do sentido original e ressignificação para se autodenominar com o mesmo signo, valorado com outro tom, como demonstra a imagem dos minions ressignificados nas mídias sociais das duas formas mencionadas:

Fonte: Facebook ${ }^{12}$

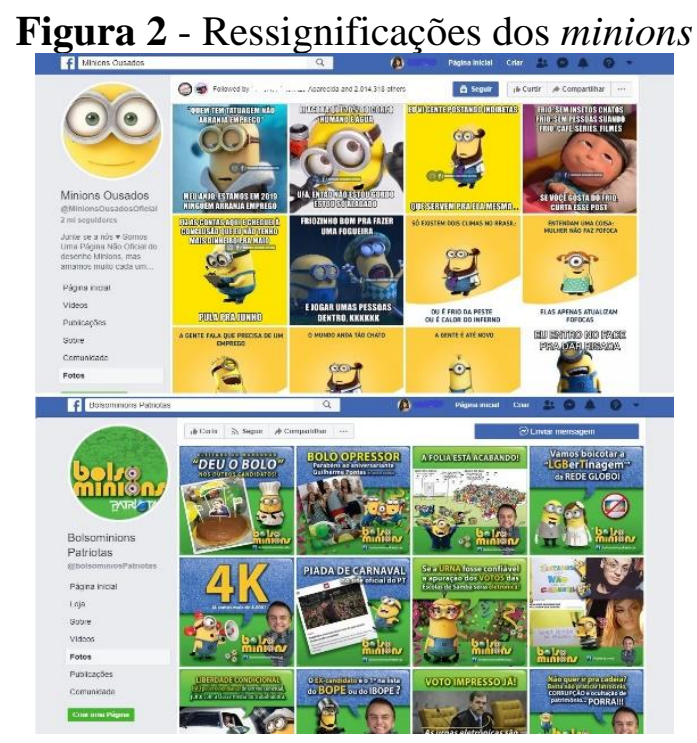

Uma estratégia para se pensar a relação produção e produto cultural massivo em salade-aula é a discussão sobre essa temática. Isso pode ser feito como acontecimento ao ver os produtos invadindo a sala (tem muito material escolar com os minions). A abordagem poderia ser por meio de perguntas sobre por que gostam dos minions, se sabem o que simbolizam e, em seguida, elaborar atividades de estratégia sobre propagandas e compra e venda, a depender do 
ano, uma feirinha com preços e contas para se pensar valor (econômico, político e social). Outra atividade poderia ser um debate sobre planos de governo (se fosse em época de eleição, com a discussão sobre os termos e as significações dos minions e dos bolsominions), entre outras, a fim de aguçar o senso crítico acerca do consumo e a tomada de consciência possível.

As práticas de linguagem surgem não de uma maneira abstrata e desconexa, mas contextualizada, em resposta, retrospectiva e prospectiva, a outros enunciados, com significações diversas, a partir das vivências únicas e singulares dos sujeitos sociais. Isso ocorre em quase todas as esferas da atividade, pois a língua, de acordo com os estudos bakhtinianos, é viva (VOLÓCHINOV, 2017 [1929]) e os enunciados, embora com acabamentos determinados, abertos a outras respostas.

\section{Considerações finais}

Mais do que praticar uma leitura passiva e receber uma obra - seja de configuração literária, animada, em quadrinhos ou qualquer outra - como atividade isolada e acabada, o aluno - sujeito inserido em uma era de grande fluxo de conteúdo transmidiático - consumirá os produtos a seu alcance de forma participativa, interativa e coletiva, como é típico da cultura da convergência que caracteriza esse momento histórico de maneira ímpar. Por se configurar como um espaço de encontro entre antigas e novas mídias, há uma interação entre produção, produto e consumo/nova produção.

O fluxo intenso de conteúdo, realizado por múltiplas plataformas midiáticas, a cooperação entre mercados e o comportamento migratório dos públicos nos meios de comunicação em busca de conteúdo de entretenimento é o que define a convergência de Jenkins. Para o autor, no entanto, esse fluxo não é o todo que a compõe. Ela também se caracteriza por ocorrer nos consumidores-sujeitos, a partir da interação com os outros.

Como o fenômeno é um processo dependente da relação entre os sujeitos produtor e consumidor, não há eficácia sem essa interação. A participação ativa dos sujeitos-consumidores faz circular a gama infinita de conteúdos disponíveis acerca de um determinado produto, por meio de diferentes sistemas de mídias. Por "participação ativa", compreendemos as manifestações da linguagem (constituídas como posicionamentos político-ideológicos e sócio culturais) em atos enunciativos diversos.

Para os estudos bakhtinianos, qualquer manifestação de linguagem (qualquer enunciado) é responsiva. $\mathrm{HP}$ e $\mathrm{O} \mathrm{Meu}$ Malvado Favorito, dois fenômenos massivos mundiais, 
ilustraram esse processo de consumo de produção massiva e produtos culturais como participação ativa dos sujeitos, especialmente, pelas redes sociais.

Por meio deles, fundamentadas no Círculo russo e nas teorias da convergência, de Lévy e da transmídia, de Jenkins, relativizamos os postulados da Escola de Frankfurt, produzidos num momento histórico específico, com pensamento voltado à manipulação política da arte, utilizada como estratégia de alienação pelo governo (o caso do cinema estudado por Adorno exemplifica exatamente esse processo).

Extremamente fecundo pensarmos, na sala-de-aula, sobre esses processos de produções e produtos culturais para aguçar a criticidade, com propostas que levem esses enunciados, a partir das experiências dos alunos-sujeitos, como objetos de letramentos. Daí a importância das rápidas ideias sugeridas neste artigo, que reflete sobre o papel da escola e propõe, a partir do fandom de duas produções massivas, atividades crítico-dialógicas com enunciados de materialidades variadas e gêneros diversos. A relevância social de pensarmos a escola como espaço (ainda, mesmo que desvalorizado pelos governantes do país) oportuno para formar e desenvolver a cidadania consciente.

A formação estimulante e respeitosa nasce da relação entre o canônico e o não-canônico. Os multiletramentos surgem como atos sociais e as aulas como acontecimento. Nesse sentido, tudo é material de aula: desde os produtos de consumo dos minions, as páginas do Facebook, as escritas interativas a partir de $H P$ até os clássicos da literatura e textos filosóficos. A importância desses discursos transitarem de maneira concomitante e sem juízo de valor na escola como material de nossas práticas pedagógicas é a de sair das bolhas sociais institucionais e partir da vivência do outro para que a aprendizagem efetiva aconteça, como já nos ensinou Paulo Freire.

Os ambientes midiáticos constituem nossa sociedade e ignorar as práticas sociais só servirá para proliferar o desinteresse pela aprendizagem, a apatia social e a robotização que reproduz sem pensar porque acostumada a seguir ordens e não a pensar e a ser autônomo. Queremos e lutamos por uma educação de qualidade, crítica e cidadã. Isso passa pelo respeito ao outro como ser que, diferente de mim, pensa, sente e atua no mundo, com suas experiências, tão essenciais quanto outras tantas. Quebrar com os preconceitos (sobre linguagens, práticas sociais, arte e sujeitos) é urgente e ainda o nosso maior desafio para prosseguirmos na construção de nossa pedagogia cidadã. 


\section{REFERÊNCIAS}

ADORNO, T. W. Indústria cultural e sociedade. São Paulo: Paz e Terra, 2002.

BAKHTIN, M. M. Para uma filosofia do ato responsável. São Carlos: Pedro \& João, 2010 [1920-24].

BAKHTIN, M. M. Estética da criação verbal. 6. ed. São Paulo: Martins Fontes, 2011.

GERALDI, J. W. A aula como acontecimento. São Paulo: Pedro \& João Editores, 2015.

JENKINS, H. Cultura da convergência. São Paulo: Aleph, 2009.

KNEBEL, F. C. M.; HILDEBRAND, H. R. "É proibido acessar as redes sociais? Uma reflexão sobre o ensino e aprendizagem de Língua Portuguesa através das Redes Sociais no Ensino Fundamental”. Revista Teccogs, PUC, São Paulo. n. 7, 156 p, jan./jun. 2013. Disponível em: http://www4.pucsp.br/pos/tidd/teccogs/dossies/2013/edicao_7/1proibido_acessar_as_redes_sociais-flavia_cristina_martins_knebelhermes_renato_hildebrand.pdf. Acesso em: 23 maio 2019.

LÉVY, P. A inteligência coletiva: por uma antropologia do ciberespaço. São Paulo: Edições Loyola, 2007. [1994].

LÉVY, P. Cibercultura. São Paulo: 34, 2000. [1997]

MACHADO, I. Gêneros Discursivos. In: BRAIT, B. (Org,). Bakhtin Conceitos-Chave. São Paulo: Contexto, p. 151-166, 2014.

MEDVIÉDEV, P. N. O método formal nos estudos literários: introdução crítica a uma poética sociológica. São Paulo: Contexto, 2012.

PAULA, L. de; FIGUEIREDO, M. H. de; PAULA, S. L. de. "O marxismo no/do Círculo de Bakhtin”. In: STAFUZZA, G. B. (Org). Slovo - O Círculo de Bakhtin no contexto dos estudos discursivos. Curitiba: Appris, p. 79-98, 2011.

VOLÓCHINOV, V. Marxismo e filosofia da linguagem: problemas fundamentais do método sociológico na ciência da linguagem. São Paulo: 34, 2017 [1929].

\section{Como referenciar este artigo}

PAULA, Luciane de; BARISSA, Ana Beatriz Maia; OLIVEIRA, Natasha Ribeiro de. Produções e produtos culturais na sala-de-aula: uma análise crítico-dialógica do Fandom de Harry Potter e da franquia Meu Malvado Favorito. Revista Ibero-Americana de Estudos em Educação, Araraquara, v. 14, n. esp. 4, p. 2071-2087, dez., 2019. E-ISSN: 1982-5587. DOI: https://doi.org/10.21723/riaee.v14iesp.4.12935

Data de submissão: 15/06/2019

Data de aceite: 18/07/2019

Data de publicação: 01/09/2019

RIAEE - Revista Ibero-Americana de Estudos em Educação, Araraquara, v. 14, n. esp. 4, p. 2071-2087, dez., 2019. E-ISSN: $1982-5587$. DOI: https://doi.org/10.21723/riaee.v14iesp.4.12935 